\section{LA ALDEA GLOBAL}

Marshall Mac L uhan y B.R. Powers, Editorial Gedisa, 1990

Como se sabe, la figura del pensador canadiense Marshall Mac Luhan generó mucha polémica, particularmente a finales de los 60 y durante los 70 . Aunque, con mucho menor intensidad, el debate sobre sus ideas ha continuado después de su muerte, ocurrida en 1980.

No es fácil intentar un balance del pensamiento de Mac Luhan, básicanente porque siempre es problemático sintetizar una reflexión que no se parece en mucho a lo que uno esperaría de una propuesta intelectual, convencionalmente hablando. Sin embargo, la no linealidad del pensamiento de Mac Luhan no es la dificultad principal; lo complicado en este caso es abordar un autor que escribe libros de inesperado formato, que inventa términos, que estira analogías, que utiliza metáforas curiosas, que se apoya en Shakespeare, el mito de Narciso, la física cuántica, las parábolas de Buda, la música de los Beatles o la neurofisiología.

Si lo plantean ya para cl lector, los textos de Mac Luhan plantean al intérprete un problema de competencia, de idoneidad en el manejo de una variedad impresionante de fuentes. Algunos críticos zanjaron la cuestión sosteniendo que nos hallábamos frente a un charlatán, ingenioso y brillante, pero charlatín al fin.

Llama poderosamente la atención que no se disponga de un balance apropiado sobre las propuestas de Mac Luhan; la teoría de la comunicación de la década de los 80 , más bien ha eludido el ajuste de cuenta mediante el expediente de ignorarlas o limitar la alusión a unas notas marginales.

El hecho es que, junto con el fin de los 80 , Mac Luhan vuelve a la carga, póstumamente, gracias a la publicación de "La Aldea Global", un trabajo que recoge una investigación a la que el autor canadiense y B.R.Powers dedicaron todo su tiempo entre 1976 y 1979 . Este texto forma parte de los Documentos Mac Lulan, material que reúne la obra no publicada del pensador, desarrollada en el Centro para la Cultura y la T'ecnología de la Universidad de Toronto, Canadá.

Lin lo sustantivo, "La Aldea Global" contiene un modelo para estudiar el impacto de las tecnologías sobre la sociedad. El núcleo central del modelo es la jdea de Téxade, una estructura que, según los aulores, descubre los aspectos formales de todas las formas de conunicación, una figura que permitiria predecir los cambios generados por nuevas tecnologías. A quién le resulte familiar la obra anterior de Mac Luhan, advertirá de inmediato su giro inicial. Mientras en "La comprensión de los medios. como extensiones del hombre" (1964), Macl uhan argumentaba la inposibilidad humana de pereibir los impactos de una tecnología especifica en el momento histórico en que éstos se están produciendo - cuestión fundanenfada en la tesis de la narcosis del sensorio humano ante
Cada nueva extensión tecnológica del cuerpo-, ahora, este Mac Luhan póstumo, propone un modelo predictivo que permitiria vencer la inconciencia, el sonambulismo y la hipnosis cultural.

Según Mc Luhan y Powers, todas las formas de comunicación (o sea, todas las tecnologías): a) intensifican algo; b) vuelven obsolcto algo; c) recuperan algo dejado de lado tiempo atrás, y d) sufren una inversión cuando se las lleva más allá de los límites de su potencial.

Se trata, sin duda, de un libro sorprendente, que junto con recoger temas macluhianos característicos (como la oposición entre espacio visual y espacio acústico; entre figura y fondo, etc.), contiene excelentes capítulos sobre los efectos globales de la tecnología del sonido. Está incluido, igualmente, un llamativo capítulo sobre los hemisfcrios cerebrales derecho e izquierdo, y su relación con las experiencias de comunicación. Por otra parte, incluye un glosario de las consecuencias texádicas de 43 tccnologías. Además, las notas y referencias completan un material valiosísimo sobre el fenómeno de las comunicaciones.

En suma, "La Aldea Global" constituye una lectura obligada sobre la materia; y aunque las tesis que contiene pucden generar todas las oposiciones que se quiera, no podrá ponerse en duda la inaginación, el talento y la originalidad que se respiran en cada página.

EDISON OTERO

\section{VIOLENCIA POLITICA POPULAR EN LAS "GRANDES ALAMIIDDAS", 1947-1987}

Gabriel Salazar. Edicioncs SLR, Santiago, 1990, 433 págs.

Con este texto, el primero de dos volúmenes, G. Salazar of rece un análisis profundo y sistemático del problema de Ia violencia política en la sociedad chilena, referida específicanente a la violencia política de los sectores populares urbanos de la ciudad de Santiago durante las últimas cuatro décadas de la historia política del país.

En la Introducción G. Salazar aboga por la constitucićn de una verdadera y organizada Ciencia Política, "esto es, no la interpretación solista - genial o no- de algún intelectual o politico de nota, sino el surgimiento de una o más generaciones de intelectuales que investiguen trascendentalmente el proceso histórico en que se debate la sociedad nacional, y la constitución social de actitudes epistemológicas que superen las intrascendencias del modernismo intelectual" (pág. 20).

A su juicio, seria entonces un error negar la existencia histórica del conflicto, "dando por verificada a priori la hipotesis de yue la sociedad chilena constituye un soloy honogéneo actor histórico y que, superada la etapa convuisa de la 'modernización' (obra coronada por el general P'inchet), está en condiciones de dar st salto a la etapa superior de "modernidad" (pág. 21).

No hay, por lo tanto, una única perspectiva epistemo- 